\title{
Lateral Subcutaneous Internal Sphincterotomy in Treatment of Anal Fissure
}

\author{
D. C. HOFFMANN, ${ }^{*}$ M.B., F.R.A.C.S. ; J. C. GOLIGHER, † CH.M., F.R.C.s.
}

\begin{abstract}
Cummary: One hundred and three patients with anal fissures have been treated by lateral internal sphincterotomy performed by a subcutaneous myotomy technique, and 99 have been successfully followed up for from 3 to 24 months (mean 11 months). The operation was free from significant complications, apart from slight reactionary bleeding in one case and a perianal abscess in another. The fissure persisted or recurred in three cases, in one of which a further lateral sphincterotomy was performed, with cure. Various minor defects of anal continence were noted in 12 cases. These results have been found to be superior to those obtained previously in the same surgical unit with open posterior internal sphincterotomy and simple sphincter-stretching respectively in the treatment of anal fissure. The most reliable and satisfactory operation at present available for this condition seems, therefore, to be lateral subcutaneous internal sphincterotomy.
\end{abstract}

\section{Introduction}

Internal sphincterotomy was originally performed for the surgical treatment of anal fissure under a complete misapprehension. Miles (1939) stated that he had been treating idiopathic fissure-in-ano for many years by "pectenotomy," or division of what he called the "pecten band" in the lower part of the anal canal. This apparent fibrous band was eventually shown by Eisenhammer (1951) and Goligher, Leacock, and Brossy (1955) to be the spastic prominent lower edge of the internal sphincter. Milligan and Morgan (1934) and Gabriel (1948), in the course of excising anal fissures, made a practice of dividing what they maintained was the spastic, subcutaneous part of the external sphincter. Eisenhammer (1951) and Goligher et al. (1955), however, demonstrated beyond doubt that this band of muscle was in fact the wrongly identified inferior margin of the internal anal sphincter.

Credit for suggesting the treatment of anal fissure by internal sphincterotomy alone under its correct designation must rest with Eisenhammer (1951). The method favoured by him for this manœuvre was to divide the lower half of the muscle by an incision in the midline of the posterior wall of the anal canal-usually through the fissure itself-the resulting wound being left open to heal by granulation. The excellent results claimed by Eisenhammer $(1951,1959)$ for this operation were fully substantiated by the experience of Morgan and Thompson (1956) and Lockhart-Mummery (1957), but a more exact appraisal by Bennett and Goligher (1962), while confirming the great efficacy of internal sphincterotomy in curing anal fissure, disclosed two not insignificant disadvantages of this operation. Firstly, the open wound in the anal canal often took a surprisingly long time to heal, four weeks being the average period and six to seven weeks being not uncommon. Secondly, there was a disturbingly high incidence of minor imperfections of anal continence after sphincterotomy, as shown by occasional lack of control for flatus or faeces or inadvertent slight leakage of faecal matter, leading to soiling of the underwear. Similar findings were subsequently reported by Magee and Thompson (1966).

So impressed were Watts, Bennett, and Goligher (1964) by these drawbacks of internal sphincterotomy that they decided

- Lecturer, University Department of Surgery, the General Infirmary at Leeds. t Professor, University Department of Surgery, the General Infirmary at
Leeds. to treat anal fissures for a trial period by the time-honoured method of simple sphincter-stretching. This operation had the advantage that it left no anal wound, and an earlier return to work was therefore usually possible after it. Minor disturbances of anal control, however, were found to occur in a proportion of the patients, though they were less common than after sphincterotomy. The main weakness of sphincterstretching turned out to be the higher incidence of persistent or recurrent fissures, which were encountered in $16 \%$ of the cases as against $7 \%$ after sphincterotomy.

There would thus seem to be something to be said for retaining internal sphincterotomy in the treatment of anal fissure if its ill effects could be lessened or eliminated by attention to operative technique. In the prevention of disturbances of continence after sphincterotomy Eisenhammer (1959) warned particularly against division of more than the lower half of the internal sphincter, but Bennett and Goligher (1962) found that the frequency of such disorders was little affected by the extent of the sphincterotomy. Bennett and Duthie (1964) thought that the relatively insensitive median cicatricial furrow in the dorsal wall of the anal canal after internal sphincterotomy allowed faecal matter to escape surreptitiously from the rectum to the exterior without evoking the normal sphincter response.

The possibility that a lateral sphincterotomy might cause a less prominent groove than a posterior one and be followed by less disturbance of function was suggested by Eisenhammer (1959) and Bennett and Goligher (1962). More recently Parks (1967) strongly recommended lateral sphincterotomy through a short circumferential incision in the skin outside the lateral anal verge, which is subsequently closed by suture. The great advantage of this method, which is also favoured by Hawley (1969), is that it avoids an open wound in the anal canal itself. Even simpler and more expeditious is the technique of lateral subcutaneous internal sphincterotomy, described by Notaras $(1968,1969,1970)$, in which the lower part of the internal sphincter is divided as in doing a subcutaneous tenotomy, which leaves virtually no wound at all. This is the method to which we have been most attracted, and since mid-1968 it has been used by us almost exclusively for the treatment of anal fissure. In this paper we report our experiences with this operation.

\section{Patients}

Between May 1968 and February 1970103 patients were treated for fissure-in-ano by lateral subcutaneous internal sphincterotomy. In 85 the fissure was chronic in nature and the remainder suffered from acute fissures that had not responded to conservative measures. Of the 103 patients, unfortunately four failed to respond to repeated requests to attend for review, but 99 reported and were personally interviewed and examined at regular intervals. They form the basis of this study and comprise 62 males and 37 females, the average age being 42 years. The mean length of follow-up at the time of review was 11 months.

Before operation all patients were closely questioned about any disturbance of anal control. Postoperatively each patient was routinely interrogated and examined one week after operation and again at four weeks and thereafter every three months. At these attendances special note was made of the state of healing of the fissure, of any complications of the 
operation, of the time of return of the patient to work, and of any alterations of anal continence in the form of impaired control for flatus or faeces or faecal soiling of the perianal region as described by Bennett and Goligher (1962).

\section{Operative Technique and Aftercare}

The operation was usually performed as an outpatient procedure under general anaesthesia, and only in exceptional circumstances was overnight admission necessary. With the patient in the lithotomy position a bivalve speculum, such as our own pattern (Goligher, 1961), was introduced into the anal canal and rotated so that the handle lay to the patient's right and the blades were placed in front and behind. The instrument was then gently opened to a diameter approximating to two fingerbreadths. This manœuvre had the effect of exposing the left lateral wall of the anal canal and of rendering the lower margin of the internal sphincter in that sector taut and easily palpable-sometimes even visible-as a definite curvilinear prominence. For the myotomy a von Graefe cataract knife was used.

Unlike Notaras (1968, 1969), who divided the internal sphincter from within outwards, we preferred to introduce the knife on the outer side of this muscle and to cut medially. Accordingly, the point of the blade was inserted through the perianal skin immediately lateral to the lower edge of the internal sphincter and passed vertically upwards in the intersphincteric plane till it was adjudged to lie at or just above the level of the pectinate line. By means of delicate strokes of the blade in the direction of the anal canal the lower half of the internal sphincter was then divided, care being exercised not to penetrate the lining of the anal canal (Fig., B). A useful precaution to avoid such penetration was to leave a few of the innermost fibres of the muscle undivided and, after the knife had been withdrawn, to rupture them by firm lateral pressure with the finger (Fig., C.). This pressure was maintained for two to three minutes to secure haemostasis, while the retractor was removed from the anal canal, and a pad of cotton-wool was then applied and maintained in position by a firm $\mathrm{T}$-bandage. We have not usually removed any associated sentinel skin tags, unless they were particularly large and troublesome, for we were anxious to confine the operation so far as was possible to sphincterotomy alone during this trial period.

The patients were allowed home within a few hours. They were given oral pethidine to control postoperative pain for the first night or two, and a mild aperient such as liquid paraffin was prescribed to ensure easy bowel actions for a few days. As regards local attention to the anal region the patients were advised to have a daily bath, preferably after defaecation, and to apply a dry dressing if there was any discharge.

\section{Results}

Immediate Relief of Pain and Healing of Fissure.-Satisfactory relief of pain was achieved in all patients but one. Usually it occurred within a few days, and no fewer than 92 patients were quite free of pain when questioned one week after operation. In a further six patients the subsidence of the pain was much less dramatic and took varying periods of time up to a month after the sphincterotomy. Because patients were as a rule seen only one week, one month, and three months after operation, the exact time it took for each fissure to heal completely could not be assessed, but only the state of healing at these set intervals. One week after operation the fissure was deemed to be healed in 31 of the 99 patients examined, while at one month complete healing was recorded in all but 4 of the 99 cases reporting at that stage. In two patients the fissure remained open and unhealed, though painless, up to the final review at 9 and 10 months respectively.

Time Off Work.-The length of the period during which the patients remained off work after operation was often determined largely by social and economic factors rather than the strict needs of surgical care, and averaged about seven days. It is significant that active housewives almost invariably resumed full domestic duties within two to three days of the sphincterotomy.

Recurrence.-Patients were deemed to be suffering from a recurrence of their complaint if pain was not relieved or it recurred after operation, or if an open fissure was found to be present on examination. One patient continued to experience pain at defaecation, and his fissure failed to heal. Reexamination under general anaesthesia eight weeks after operation confirmed that the fissure was quite unhealed and showed that the sphincterotomy had been unusually limited in its extent. Further internal sphincter was therefore divided up to the pectinate line and a large oedematous sentinel skin tag was removed. This second more adequate sphincterotomy was followed by rapid relief of pain and by complete healing of the fissure, but for the purposes of this study we have regarded this case as an example of recurrence. Two other patients, though completely relieved of anal pain, had persistently unhealed anal fissures. One of these occurred laterally at the site of an abscess complicating the sphincterotomy. In all, then, 3 of the 99 cases reviewed were considered to have recurrence, and on that score to represent failures of the operation.

Complications of the Sphincterotomy.-One patient had a brisk reactionary haemorrhage from the sphincterotomy stab wound two hours after operation and was admitted to hospital overnight for observation. The bleeding was satisfactorily controlled by direct pressure and blood transfusion was not

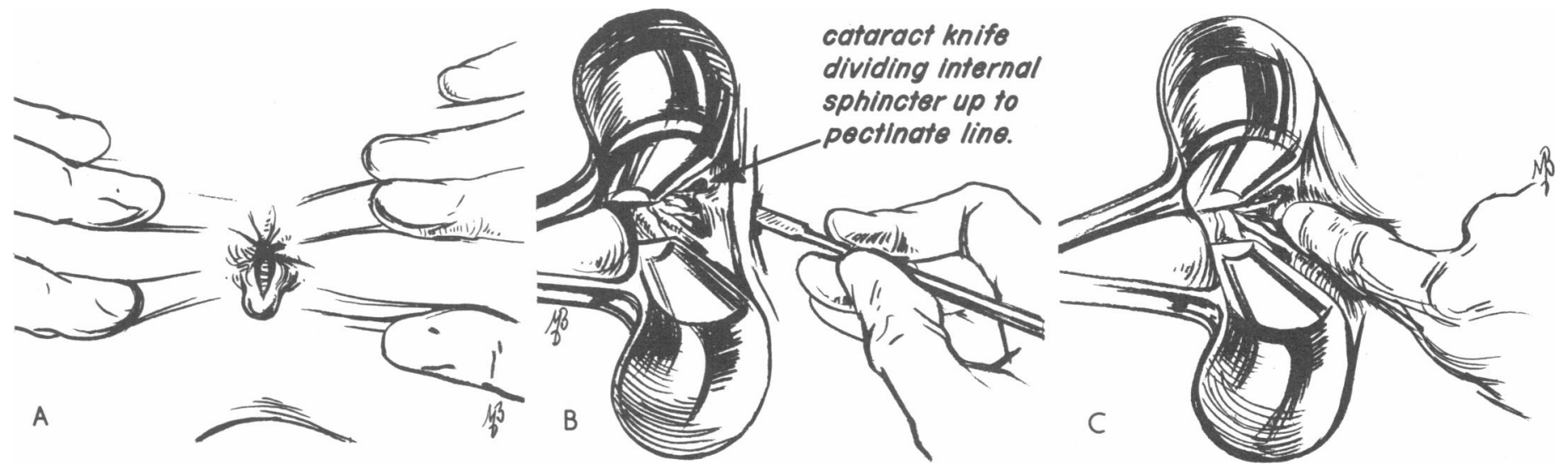

Fig. 1.-Operation of lateral subcutaneous internal sphincterotomy for anal fissure. A. Fissure with sentinel tag situated in the midline posteriorly. B. Bivalve speculum in position and opened to display the left lateral wall of the anal canal. Cataract knife has been inserted through the perianal skin lateral to the lower edge of the internal sphincter up to the level of the pectinate line and has severed the fibres of the muscle almost through to the cutaneous lining. C. After withdrawal of the knife, pressure by the finger-tip on the lower half of the lateral wall of the anal canal ruptures any residual fibres of the internal sphincter at this site. 
required. The subsequent course was uneventful. Another patient developed a perianal abscess and subsequent fistula at the site of the sphincterotomy, which required to be laid open 28 days after operation. Though this patient was completely relieved of his pain he developed a persistent granulating fissure in the situation of the abscess. It is remarkable that significant haematoma formation requiring further surgical intervention did not occur in any case, but minor ecchymoses were observed postoperatively in 22 cases. Two patients complained that following sphincterotomy they had troublesome prolapse of haemorrhoids, in one case requiring urgent haemorrhoidectomy.

Alterations of Anal Sphincter Function.-In this connexion the important observations were the findings at the latest follow-up interview, which in no case was less than three months after operation. At this stage 6 of the 99 patients interrogated were unable to control flatus satisfactorily, and one had in addition occasional incontinence for faeces. Seven patients complained of some soiling of their underclothes, but this was usually very slight. Twelve patients suffered one or more of these disturbances of anal continence, which they were emphatic had not been present before operation.

\section{Discussion}

Perhaps the most useful way to consider the achievements of lateral subcutaneous internal sphincterotomy in this series is to compare the results obtained by it with those previously reported by us after open posterior internal sphincterotomy (Bennett and Goligher, 1962) and sphincter-stretching (Watts et al., 1964) respectively. Admittedly such a comparison falls short of a properly controlled clinical trial so far as objectivity and reliability are concerned, but it should be pointed out that the three groups of patients, who were all treated on the same surgical service, were very similar, and that the exact same criteria of assessment of results were applied throughout. We believe, therefore, that a comparative appraisal of the results secured by us with the three operations in this way should be of value.

In only 3 of the 99 patients treated by lateral subcutaneous internal sphincterotomy did the fissure persist or recur, and only one of these recurrences required further operative treatment (by a more extensive sphincterotomy), which was successful. This $3 \%$ recurrence rate compares not unfavourably

Incidence of Minor Disturbances of Anal Continence Following Various Operations for Anal Fissure

\begin{tabular}{|c|c|c|c|c|c|}
\hline \multirow{3}{*}{$\begin{array}{l}\text { Type of } \\
\text { Operation }\end{array}$} & \multirow{3}{*}{$\begin{array}{c}\text { No. of } \\
\text { Patients } \\
\text { Reviewed }\end{array}$} & \multicolumn{4}{|c|}{$\begin{array}{l}\text { Percentage Incidence of } \\
\text { Minor Defects of Anal Control }\end{array}$} \\
\hline & & \multicolumn{2}{|c|}{$\begin{array}{l}\text { Impaired } \\
\text { Control for }\end{array}$} & \multirow{2}{*}{$\begin{array}{c}\text { Faecal } \\
\text { Soiling of } \\
\text { Underwear }\end{array}$} & \multirow{2}{*}{$\begin{array}{c}\text { One } \\
\text { or More } \\
\text { Defects }\end{array}$} \\
\hline & & Flatus & Faeces & & \\
\hline 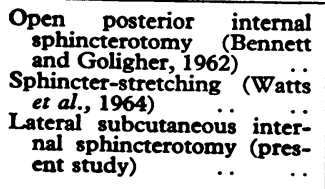 & $\begin{array}{r}127 \\
90 \\
99\end{array}$ & $\begin{array}{l}24 \\
12\end{array}$ & $\begin{array}{r}11 \\
2 \\
1\end{array}$ & $\begin{array}{l}28 \\
20\end{array}$ & $\begin{array}{l}43 \\
28 \\
12\end{array}$ \\
\hline
\end{tabular}

with the incidence of recurrence of $7 \%$ after open posterior internal sphincterotomy (Bennett and Goligher, 1962) and $16 \%$ after sphincter-stretching (Watts et al., 1964). Equally satisfactory were the results as regards anorectal function after lateral subcutaneous internal sphincterotomy (see Table), for it will be seen that the proportion of patients who had minor defects of anal control after this operation was smaller than that after the other two operations. Very gratifying also has been the virtual absence of "surgical" complications relating to the stab wound used for the sphincterotomy in the subcutaneous technique. Contrary to what might have been expected, haematoma formation did not occur in any case, and only one wound became infected.

By all standards, then, lateral subcutaneous internal sphincterotomy would seem to have a small but definite advantage over the other two operative methods contrasted, and we have no hesitation in recommending that it should replace these operations in the routine treatment of anal fissure. It would be interesting to compare the results of lateral internal sphincterotomy as performed by this subcutaneous technique with those obtained by open dissection through a perianal incision with subsequent suture (Parks 1967), on which Hawley (1969) reported favourably, and by simple incision of the muscle through the lining of the anal canal as in open posterior internal sphincterotomy (Eisenhammer, 1959; Bennett and Goligher, 1962; Hardy and Cuthbertson, 1969). Unfortunately we have only a few patients treated by these alternative methods of lateral internal sphincterotomy, insufficient for a worth-while comparison. But we find it hard to believe that these other operations could surpass the accomplishments of the subcutaneous technique, which has the additional advantage over the method of open dissection through a perianal incision that it is much easier and quicker to perform, being in fact a momentary operation.

Our conclusion is that of the operative methods currently available for the treatment of idiopathic anal fissure the most convenient and satisfactory is lateral subcutaneous internal sphincterotomy, and this operation has now become our standard procedure for this condition.

\section{REFERENCES}

Bennett, R. C., and Duthie, H. L. (1964). British fournal of Surgery, 51, 355. Bennett, R. C., and Goligher, J. C. (1962). British Medical fournal, 2, 1500. Eisenhammer, S. (1951). South African Medical fournal, 25, 486.

Eisenhammer, S. (1959). Surgery, Gynecology and Obstetrics, 109, 583. Gabriel, W. B. (1948). Principles and Practice of Rectal Surgery, 4th edn. London, Lewis.

Goligher, J. C. (1961). Surgery of the Anus, Rectum and Colon. London, Cassell. Goligher, J. C., Leacock, A. G., and Brassy, J. J. (1955). British fournal of

Hardy, K. J., and Cuthbertson, A. M. (1969). Australian and New Zealand fournal of Surgery, 39, 91 .

Hawley, P. R. (1969). British fournal of Surgery, 56, 915.

Lockhart-Mummery, H. E. (1957). In Operative Surgery, ed. C. Rob and R. Smith, vol. 3, p. 11. London, Butterworths.

Miles, W. R., and Thompson, H. R. (1966). Gut, 7, 190.

Milligan, E. (1939). Rectal Surgery. London, Cassell.

Milligan, E. T. C., and Morgan, C. N. (1934). Lancet, 2, 1213.

Morgan, C. N., and Thompson, H. R. (1956). Arrnals of the Royal College of Surgeons of England, 19, 88 .

Notaras, M. J. (1968). Personal communication.

Notaras, M. J. (1969). Proceedings of the Royal Society of Medicine, 62, 713.

Notaras, M. J. (1970). British fournal of Surgery. In press.

Parks, A. G. (1967). Hospital Medicine, 1, 737.

Watts, J. McK., Bennett, R. C., and Goligher, J. C. (1964). British Medical 